$6^{\text {th }}$ INTERNATIONAL ATLANTIC ECONOMIC CONFERENCE

Madrid, Spain, March 14-18, 2007

\title{
Pricing American Options in a Mild Stochastic Environment
}

\author{
Professor Moisa ALTAR, \\ Doctoral School of Finance and Banking, Academy of Economic Studies, 6 \\ Piata Romana, sect. 1, Bucharest, Romania \\ e-mail: maltar@ase.ro; altarm@gmail.com \\ http://www.dofin.ase.ro \\ phone: +40-744-529831 \\ fax: $+40-21-3129549$ \\ and \\ Professor Judita SAMUEL \\ Romanian - American University, Bucharest, 1, Bd. Expozitiei, sect. 1, \\ Bucharest, Romania \\ e-mail: jsamuel@csm.ro \\ phone: +40-723-371036
}

JEL Clasification : C 61, D 99,E 31, E 41, E 62, E 63, H 62, H 63, O 41.

Macro focus 


\section{PRICING AMERICAN OPTIONS IN A MILD STOCHASTIC ENVIRONMENT}

\section{Introduction}

The problem of pricing derivative financial products is central to the theory of capital markets.

An option is a financial contract conveying its owner the right of buying or selling a financial asset (underlying asset) at a preset strike price $K$, at a fixed expiration date $T$ (maturity). Unlike European options, which can be exercised only at maturity date, an American option can be exercised at any time $t$ prior to the maturity date.

Most of the option pricing methods, starting with the well-known Black-Scholes model (1973), are based on the assumption that the market uncertainty can be modeled by a Wiener process. In this context, while it is possible to obtain convenient analytical option pricing formulae for European options, it is very difficult to obtain "exact" results for American options.

In the present paper, we assume that the market uncertainty is modeled by a more regular stochastic process, which was called, by A. Halanay, a mild stochastic environment. In this context, we are able to obtain precise stopping rules, determining the exact exercise time and the exact price of an American option.

\section{The “Mild Stochastic Environment” (MSE) hypothesis}

The concept of mild stochastic environment was proposed by the late Professor Aristide Halanay from the University of Bucharest, Romania.

It refers to the stochastic process obeyed by the underlying stock price, which is supposed to satisfy the assumption:

$$
\lim _{\tau \rightarrow 0} \frac{[S(t+\tau)-S(t)]^{2}}{\tau}=0
$$

Under this assumption, the price of a derivative product (e.g. call or put) satisfies a first order partial differential equation, unlike in the case of the Black-Scholes model, where the corresponding partial differential equation is of second order. This feature leads to simpler option pricing formulae for European, as well as American options.

In the paper Samuel (1999), we obtained for the "fair price” $D$ of a European derivative product on a stock $S$ the formula:

$$
D(t, S, T)=\exp [-r(T-t)] R(\exp [r(T-t)] S)
$$

where $D(t, S, T)$ represents the price at time $t$ of a derivative product of maturity $T$ on a stock having the price $S$, and $R(S)$ represents the "reward" or the price at maturity of the derivative (i.e. $R(S)=D(T, S, T)$ ). This reward represents a boundary condition for the partial differential equation satisfied by the derivative price.

Thus, in the case of a European call, we have $R(S)=\max \{S-K, 0\}$, where $K$ is the exercise price and, accordingly, we found for the price at time $t$ of a European call of maturity $T$ on a stock having the price $S$ the formula

$$
c(t, S, T)=\max \{S-K \exp [-r(T-t)], 0\} .
$$


For the European put, the reward is $R(S)=\max \{K-S, 0\}$ and the price at time $t$ of a European put with maturity $T$ on a stock having the price $S$ is

$$
p(t, S, T)=\max \{K \exp [-r(T-t)]-S, 0\} .
$$

\section{Relationships between European and American call and put prices}

Certain general relationships between European and American call and put prices are valid, irrespective of the stochastic process obeyed by the stock price. We shall list here some of these relationships, following Hull (2000).

We use the following notations:

$K$ - exercise price;

$S$ - price of the underlying stock;

$c=c(0, S, T)$ - price of the European call of maturity $T$;

$C=C(0, S, T)-$ price of the American call of maturity $T$;

$p=p(0, S, T)-$ price of the European put of maturity $T$;

$P=P(0, S, T)$ - price of the American put of maturity $T$;

$r$ - interest rate, assumed to be deterministic and constant.

Lower and upper limits :

1. $C \leq C \leq S_{0}$;

2. $p \leq P \leq K$;

3. $p \leq K e^{-r T}$;

4. $c \geq \max \left\{S_{0}-K e^{-r T}, 0\right\}$;

5. $p \geq \max \left\{K e^{-r T}-S_{0}, 0\right\}$.

Put-call parity for European options:

$$
c+K e^{-r T}=p+S_{0} .
$$

For American options,

$$
S_{0}-K \leq C-P \leq S_{0}-K e^{-r T}
$$

We remark that, in the special case of the MSE, the European call and put prices, given in the previous section, coincide with the lower limits that appear in formulas 4 and 5 above.

\section{American call and put price on a non-dividend -paying stock (in a MSE)}

As we saw in section 2, the price at time $t$ of the European call of maturity $T$ is

$$
c(t, S, T)=\max \{S-K \exp [-r(T-t)], 0\} \text {. }
$$

In order to find the optimal exercise time (stopping time), we have to compare, at each time $t \in[0, T]$, the reward $R\left(S_{t}\right)=S_{t}-K$ that would be obtained if the call were exercised at time $t$, with $c\left(t, S_{t}, T\right)$ (the value of the option, if not exercised at $t$ ). 
We see that $c\left(t, S_{t}, T\right)-R\left(S_{t}\right)=K\left(1-e^{-r(T-t)}\right)>0, \forall t<T$.

Therefore, while $t<T$, it is always advantageous to keep the call option.

Eventually, it is optimal to exercise the call at maturity date $T$ and, therefore, $C\left(0, S_{0}, T\right)=c\left(0, S_{0}, T\right)=\max \left\{S_{0}-K e^{-r T}, 0\right\}$.

As concerns the put option, the situation is symmetrical; if it were exercised at any time $t>0$, the return would be $K-S_{t}$ (assuming that $K \geq S_{t}$ ); the price of the European put at $t$ is $p(t, S, T)=\max \{K \exp [-r(T-t)]-S, 0\}$.

Obviously, $K-S_{t}=K e^{-r(T-t)}-S_{t}$. The difference is $K\left(1-e^{-r(T-t)}\right)$; it is positive for any $0<t<T$ and decreasing. Therefore, it is optimal to exercise the put option as early as possible. The maximum return is obtained if the option is exercised at $t=0$ and is equal to $K-S_{0}$ (if $\left.K \geq S_{0}\right)$. Therefore, $P\left(0, S_{0}, T\right)=\max \left\{K-S_{0}, 0\right\}$.

Therefore, if the underlying stock pays no dividends, the American call behaves like the European call and, consequently, has the same price. This result coincides with that obtained for American calls in the Black-Scholes setting (see, e.g. Hull (2000).

As concerns American puts on stocks paying no dividends, it is generally accepted that early exercise is desirable, but analytical results are difficult to obtain in the Black Scholes setting. In the MSE environment, we were able to deduce an exact result, namely that exercise at $t=0$ is optimal.

\section{Price of an American call on a stock with one known dividend}

In this section, we shall derive a formula for the valuation of an American call on a stock which pays one known dividend. We assume that, at the ex-dividend instant $t^{*}<T$, the stock pays a dividend $D$, which induces a stock price decline of $\alpha D$.

We also assume that the stock price net of the escrowed dividend, S, obeys the MSE hypothesis.

If we denote by $Z_{t}$ the stock price cum dividend, then

$S_{t}=Z_{t}-\alpha D \exp \left[-r\left(t^{*}-t\right)\right]$ for $t<t^{*}$

and

$S_{t}=Z_{t} \quad$ for $t \geq t^{*}$

For $t<t^{*}$ we compare the return which could be obtained by exercise at that time : $S_{t}+\alpha D \exp \left[-r\left(t^{*}-t\right)\right]-K$, with the price of a European call having maturity date $t+\tau<t^{*}: c\left(t, S_{t}, t+\tau\right)=S_{t}+\alpha D \exp \left[-r\left(t^{*}-t\right)\right]-K \exp [-r \tau]$.

Obviously, the second price is larger, therefore, exercise prior to $t^{*}$ cannot be optimal. If the American call were exercised at $t^{*}-\varepsilon$ (just prior the stock going ex-dividend), then the return would be $\cong S_{t^{*}}+\alpha D-K$; if the call were not exercised until $t^{*}+\tau$, cits value at $t^{*}$ would be that of a European call of maturity $t^{*}+\tau$, i.e. $c\left(t^{*}, S_{t^{*}}, t^{*}+\tau\right)=\max \left\{S_{t^{*}}-K \exp [-r \tau], 0\right\}$. We remark that this function is increasing withrespect to $\tau$, therefore, if the option is not exercised until $t^{*}$, then it is not optimal to exercise until $T$ ( $\left(\tau=T-t^{*}\right)$. 
In conclusion, the two possible optimal exercise times are $t^{*}$ and $T$; to decide which is to be chosen, we have to compare the corresponding returns: $S_{t^{*}}+\alpha D-K$ and $S_{t^{*}}-K \exp \left[-r\left(T-t^{*}\right)\right]$.

It follows that, if $\alpha D \geq K\left(1-\exp \left[-r\left(T-t^{*}\right)\right]\right.$, then it is optimal to exercise the American call just prior to $t^{*}$; its value is that of a European call with maturity $t^{*}$ and "reward" $R(S)=\max \{S+\alpha D-K, 0\}$, namely

$$
C\left(0, S_{0}, T\right)=c\left(0, S_{0}, t^{*}\right)=\max \left\{S_{0}+(\alpha D-K) \exp \left[-r t^{*}\right], 0\right\} .
$$

If $\alpha D \leq K\left(1-\exp \left[-r\left(T-t^{*}\right)\right]\right.$, then it is optimal to exercise the American call at maturity $T$; in this case, obviously, its value coincides with that of the European call, namely

$$
C\left(0, S_{0}, T\right)=c\left(0, S_{0}, T\right)=\max \left\{S_{0}-K \exp [-r T], 0\right\} \text {. }
$$

\section{Remark}

Obviously, if $\alpha D=K\left(1-\exp \left[-r\left(T-t^{*}\right)\right]\right)$, then

$$
c\left(0, S_{0}, t^{*}\right)=c\left(0, S_{0}, T\right)
$$

and both $t^{*}$ and $T$ are optimal exercise times.

\section{Price of the American put on a stock paying one known dividend}

As in the previous section, we assume the stock price net of dividend, $S_{t}$, obeys a MSE type stochastic process.

We can view the American put as a family of European put options, indexed after the maturity date $t(0<t<T)$. For such a European put, the "reward" is:

$$
\begin{array}{ll}
R(S)=K-\alpha D \exp \left[-r\left(t^{*}-t\right)\right]-S, & \text { if } t<t^{*} ; \\
R(S)=K-S \quad \text {, if } t \geq t^{*} .
\end{array}
$$

For $\tau \in(0, t), p\left(\tau, S_{\tau}, t\right)=\exp [-r(t-\tau)] R\left(\exp \left[r(t-\tau] S_{\tau}\right)\right.$ is the price at time $\tau$ of the European put of maturity $t$.

If $t<t^{*}$ and $0 \leq \tau<t, \quad p\left(\tau, S_{\tau}, t\right)=\exp [-r(t-\tau)] K-\alpha D \exp \left[-r\left(t^{*}-\tau\right)\right]-S$;

If $t \geq t^{*}, 0 \leq \tau<t, \quad p\left(\tau, S_{\tau}, t\right)=\exp [-r(t-\tau)] K-S_{\tau}$.

Consider $\tau<t^{*}$. If the American put were exercised at time $\tau$, the return would be $K-S_{\tau}-\alpha D \exp \left[-r\left(t^{*}-\tau\right)\right]$. We compare this with the price of a European put of maturity $t<t^{*}: p\left(\tau, S_{\tau}, t\right)=\exp [-r(t-\tau)] K-\alpha D \exp \left[-r\left(t^{*}-\tau\right)\right]-S_{\tau}$.

We see that the value of the European put is smaller, hence there is no point to keep the American put and exercise it prior to $t^{*}$.

We compare now the return at time $\tau<t^{*}$ with the price of a European put of maturity $t \geq t^{*}$. We have 


$$
\begin{aligned}
& h\left(\tau, S_{\tau}, t\right)=p\left(\tau, S_{\tau}, t\right)-\left(K-S_{\tau}-\alpha D \exp \left[-r\left(t^{*}-\tau\right)\right]\right)= \\
& =K(\exp [-r(t-\tau)]-1)+\alpha D \exp \left[-r\left(t^{*}-\tau\right)\right]
\end{aligned}
$$

The above function is decreasing with respect to $t$; its maximum value is obtained for $t=t^{*}$, therefore it is not reasonable to keep the American put after $t^{*}$.

We have

$$
h\left(\tau, S_{\tau}, t^{*}\right)=\exp \left[-r\left(t^{*}-\tau\right)\right](K+\alpha D)-K .
$$

The function $h\left(\tau, S, t^{*}\right)$ is increasing with respect to $\tau$; its minimum value is obtained for $t=0$ :

$$
h\left(0, S_{0}, t^{*}\right)=\exp \left[-r t^{*}\right](K+\alpha D)-K .
$$

If $h\left(0, S_{0}, t^{*}\right)<0$, then it is optimal to exercise the American put at $t=0$.

In this case, $P\left(0, S_{0}, T\right)=\max \left\{K-\alpha D \exp \left[-r t^{*}\right], 0\right\}$.

If $h\left(0, S_{0}, t^{*}\right)>0$, then it is optimal to exercise the American put at $t=t^{*}$.

In this case, $P\left(0, S_{0}, T\right)=p\left(0, S_{0}, t^{*}\right)=\max \left\{K \exp \left[-r t^{*}\right]-S_{0}, 0\right\}$.

\section{Remark}

The condition $h\left(0, S_{0}, t^{*}\right)=0$ is equivalent to $\alpha D=K\left(\exp \left[r t^{*}\right]-1\right)$ or

$$
\frac{\alpha D}{K}=\exp \left[r t^{*}\right]-1 \text {. }
$$

If the above condition is satisfied, then either $t=0$ or $t=t^{*}$ are optimal exercise times .

The condition $h\left(0, S_{0}, t^{*}\right)<0$ is equivalent to $\frac{\alpha D}{K}<\exp \left[r t^{*}\right]-1$; in this case, the optimal exercise time is $t=0$.

If $\frac{\alpha D}{K}>\exp \left[r t^{*}\right]-1$, then $h\left(0, S_{0}, t^{*}\right)>0$ and the optimal exercise time is $t=t^{*}$.

\section{Conclusions}

American derivative securities are more difficult to value than European derivatives, because at every instant, for American derivatives, there is a positive probability of premature exercise.

Most existing results concerning the valuation of American call and put options refer to the setting proposed by the seminal paper of Black and Scholes (1973), namely they are based on the assumption that the stock price follows geometric Brownian motion. In this context, while a convenient analytical formula could be derived for the price of a European call or put option, it is very difficult to find analytical formulae for an American derivative. Although there are a number of such results ( e.g. the papers of Roll (1977), Geske (1979), Geske and Johnson (1984)), most procedures developed for the valuation of American derivatives are numerical approximations.

In the present paper, we tackle the problem of valuating American calls and puts in the mild stochastic environment setting. This assumes a more regular stochastic process followed by the stock price and, as a result, the formulae giving the price of a European call or put are linear with respect to the stock price. This property allows a precise determination of exercise times and, consequently, of exact analytical valuation formulae. 
Thus, for an American call of maturity $T$ on a stock paying no dividends, the optimal exercise time is the maturity date, therefore the price of the American call coincides with that of the European call having the same maturity date.

If the stock pays a known dividend at a known time $t^{*}$, then the optimal exercise time is $t^{*}$ or $T$, depending on the size of the dividend.

For an American put of any maturity, on a stock paying no dividends, it is optimal to exercise at $t=0$.

If the stock pays a known dividend at a known time $t^{*}$, then the optimal exercise time is $t=0$ or $t=t^{*}$, depending again on the ratio between the size of the dividend and the exercise price.

\section{References}

1. Black, F. and Scholes, M. (1973): "The Pricing of Options and Corporate Liabilities", Journal of Political Economy 81 (May-June 1973), pp. 637-59

2. Geske, R. (1979): “The evaluation of compound options”, Journal of Financial Economics 7 (1979), pp. 63-81

3. Geske,R. (1979) : "A Note on an Analytical Valuation Formula for Unprotected Call Options on stocks with known dividends”, Journal of Financial Economics 7 (1979), pp. 375-380

4. Geske, R. and Johnson, H. E (1984): "The American Put Option Valued Analytically", The Journal of Finance, vol. XXXIX, No. 5, December 1984, pp. 1511-1524

5. Hull, J. C (2000):: “Options, Futures and Other Derivatives”, Prentice Hall, 2000

6. Roll, R. (1977): "An Analytic Valuation Formula for Unprotected American Call Options on Stocks with Known Dividends”, Journal of Financial Economics 5 (November 1977), pp. 251-58

7. Samuel, Judita. (1999), “Option Pricing in a Mild Stochastic Environment”, Economic Computation and Economic Cybernetics Studies and Research, XXXIII, No. 1-4 (1999), pp. 15-18 